\title{
Laminarin-rich extract improves growth performance, small intestinal morphology, gene expression of nutrient transporters and the large intestinal microbial composition of piglets during the critical post-weaning period
}

\author{
R. Rattigan ${ }^{1}$, T. Sweeney ${ }^{2}$, S. Maher ${ }^{1}$, K. Thornton ${ }^{2}$, G. Rajauria ${ }^{1}$ and J. V. O’Doherty ${ }^{1 *}$ \\ ${ }^{1}$ School of Agriculture and Food Science, University College Dublin, Dublin 4, Republic of Ireland \\ ${ }^{2}$ School of Veterinary Medicine, University College Dublin, Dublin 4, Republic of Ireland \\ (Submitted 22 July 2019 - Final revision received 14 October 2019 - Accepted 17 October 2019 - First published online 23 October 2019)
}

\section{Abstract}

The identification of natural bioactive compounds which can prevent the post-weaning growth check and enhance gastrointestinal health in the absence of in-feed medications is an urgent priority for the swine industry. The objective of this experiment was to determine the effects of increasing dietary inclusion levels of laminarin in the first $14 \mathrm{~d}$ post-weaning on pig growth performance and weaning associated intestinal dysfunction. At weaning, ninety-six pigs (8.4 (sD 1.09) kg) (meatline boars $\times$ (large white $\times$ landrace sows)) were blocked by live weight, litter and sex and randomly assigned to: (1) basal diet; (2) basal +100 parts per million (ppm) laminarin; (3) basal +200 ppm laminarin and (4) basal $+300 \mathrm{ppm}$ laminarin (three pigs/pen). The appropriate quantity of a laminarin-rich extract ( $65 \%$ laminarin) was added to the basal diet to achieve the above dietary inclusion levels of laminarin. After $14 \mathrm{~d}$ of supplementation, eight pigs from the basal group and the bestperforming laminarin group were euthanised for sample collection. The $300 \mathrm{ppm}$ laminarin group was selected as this group had higher ADFI compared with all other groups and higher ADG than the basal group $(P<0 \cdot 05)$. Laminarin supplementation increased villus height in the duodenum and jejunum $(P<0.05)$. Laminarin supplementation increased the expression of $S L C 2 A 8 / G L U T 8$ in the duodenum, SLC2A2/GLUT2, SLC2A7/GLUT7, SLC15A1/PEPT1 and FABP2 in the jejunum and SLC16A1/MCT1 in the colon. Laminarin supplementation reduced Enterobacteriaceae numbers in the caecum $(P<0.05)$ and increased lactobacilli numbers $(P<0.05)$, total volatile fatty acid concentrations and the molar proportions of butyrate $(P<0 \cdot 01)$ in the colon. In conclusion, $300 \mathrm{ppm}$ laminarin from a laminarin-rich extract has potential, as a dietary supplement, to improve performance and prevent post-weaning intestinal dysfunction.

Key words: Laminarin: Pigs: Microbiota: Post-weaning intestinal dysfunction

For pigs reared in modern swine facilities, weaning is a source of significant stress resulting from the exposure to environmental, psychological and nutritional stressors ${ }^{(1,2)}$. This stress results in an immediate reduction in feed intake, leading to disturbances in gastrointestinal physiology, microbiology and immunology ${ }^{(3)}$. This post-weaning intestinal dysfunction creates an opportunity for colonisation by pathogenic bacteria, which when combined with reduced gut barrier function and inflammation leads to post-weaning diarrhoea ${ }^{(1)}$. The maturation of the gastrointestinal tract (GIT) is still underway during the early post-weaning period, and the optimal functioning of the GIT is a crucial factor affecting pig performance post-weaning ${ }^{(4)}$. A healthy GIT encompasses several factors such as efficient nutrient digestion and absorption, energy generation, a stable diverse microbiota, effective barrier function, effective mucosal immune system and the balanced interaction of these factors ${ }^{(5)}$.
In contrast, post-weaning intestinal dysfunction is characterised by atrophy of the small intestinal architecture, up-regulation of pro-inflammatory cytokines, proliferation of pathogenic bacteria and diarrhoea leading to reduced feed intake and performance $^{(6)}$.

Antibiotic growth promoters were included in weaner pig diets to overcome post-weaning intestinal dysfunction. However, this management strategy was banned in the EU in 2006 (EC regulation no. 1831/2003). The inclusion of pharmacological doses of zinc oxide $(\mathrm{ZnO})$ has successfully reduced diarrhoea and improved growth performance in the post-weaning period $^{(7)}$. However, concerns regarding $\mathrm{Zn}$ accumulation in soils and the relationship between $\mathrm{ZnO}$ usage and the rise in antibiotic resistance ${ }^{(8)}$ have resulted in the planned phasing out of pharmacological doses of $\mathrm{ZnO}$ in the EU by 2022 (Commission Implementing Decision of 26 June

Abbreviations: CD, crypt depth; FS, faecal scores; GIT, gastrointestinal tract; ppm, parts per million; VFA, volatile fatty acids; VH, villus height.

* Corresponding author: J. V. O’Doherty, fax +353 17161103, email john.vodoherty@ucd.ie 
2017, C(2017) 4529 Final). The EU Commission has also agreed to impose further restrictions on the use of antibiotics in farm animals from 2022, including a ban on the preventative use of antibiotics in groups of animals ${ }^{(9)}$. Thus, there is an urgent requirement to find alternative feed supplements to prevent the post-weaning growth check and intestinal dysfunction in the absence of in-feed medications. As feed intake is notoriously low in the immediate post-weaning period, the use of supplements which confer benefits to GIT health and prevent intestinal dysfunction may be one way to enhance growth performance in the post-weaning period.

Brown seaweeds are a source of natural bioactive polysaccharides such as laminarin ${ }^{(10)}$. Laminarin is composed of 1,3-linked $\beta$-D-glucose residues with different degrees of branching at $\beta$ - $(1,6)$ with the extent of branching influencing its solubility ${ }^{(11)}$. As laminarin has previously demonstrated anti-inflammatory and anti-bacterial activities ${ }^{(12)}$, it may be considered as a dietary intervention to prevent intestinal dysfunction and thus improve post-weaning performance. However, the polysaccharide content and composition of seaweed extracts can vary with season of harvest, macroalgal species and extraction procedure ${ }^{(13)}$. Furthermore, the production of purified extracts is both costly and inefficient in terms of yields. Thus, the objective of the present study was to investigate the optimum inclusion level of laminarin from a $65 \%$ purified laminarin extract on the growth performance of weaned pigs. A second objective was to identify the effects of the optimum inclusion level of laminarin on weaning associated intestinal dysfunction using the following parameters: small intestinal morphology, the expression of genes involved in nutrient digestion and absorption, inflammation, mucin production, pathogen recognition and tight junctions, populations of selected bacteria and volatile fatty acid (VFA) concentrations. It was hypothesised that laminarin would enhance growth performance in the first $14 \mathrm{~d}$ post-weaning, by enhancing intestinal morphology, reducing Enterobacteriaceae, increasing the expression of nutrient transporters and digestive enzymes and reducing the expression of pro-inflammatory cytokines.

\section{Materials and methods}

All experimental procedures described in this work were approved under University College Dublin Animal Research Ethics Committee (AREC-17-19-O'Doherty) and conducted in accordance with Irish legislation (SI no. 534/2012) and the EU directive 2010/63/EU for animal experimentation.

\section{Experimental design and diets}

The experiment comprised four dietary treatments: (T1) basal diet; (T2) basal diet +100 parts per million (ppm) laminarin; (T3) basal diet +200 ppm laminarin and (T4) basal diet +300 ppm laminarin. The inclusion levels of laminarin were determined based on the previous work by Smith et al. ${ }^{(14)}$ where no further benefit was observed when the dietary laminarin inclusion level was
Table 1. Ingredient and chemical composition of basal diet ${ }^{\star}$

\begin{tabular}{|c|c|}
\hline \multicolumn{2}{|l|}{ Ingredients $(\mathrm{g} / \mathrm{kg})$} \\
\hline Wheat & $340 \cdot 0$ \\
\hline Full-fat soya & $170 \cdot 0$ \\
\hline Flaked wheat & $130 \cdot 0$ \\
\hline Soya bean meal & $105 \cdot 0$ \\
\hline Flaked maize & $70 \cdot 0$ \\
\hline Whey powder & $50 \cdot 0$ \\
\hline Soya oil & $65 \cdot 0$ \\
\hline Vitamins and minerals & 2.5 \\
\hline Sodium bicarbonate & $2 \cdot 0$ \\
\hline Monocalcium phosphate & 4.0 \\
\hline Calcium carbonate (limestone) & $6 \cdot 0$ \\
\hline Salt & $2 \cdot 0$ \\
\hline Lysine $\mathrm{HCl}$ & 4.0 \\
\hline DL-Methionine & 1.5 \\
\hline L-Threonine & 1.5 \\
\hline \multicolumn{2}{|l|}{ Chemical analysis } \\
\hline DM & $866 \cdot 1$ \\
\hline Crude protein $(\mathrm{N} \times 6.25)$ & 190 \\
\hline Digestible energy $(\mathrm{MJ} / \mathrm{kg}) \dagger$ & 14.95 \\
\hline Ash & 48.4 \\
\hline Neutral-detergent fibre & 114.00 \\
\hline Lysine† & 13.5 \\
\hline Methionine and cysteine $\dagger$ & 7.4 \\
\hline Threonine† & 7.9 \\
\hline Tryptophan† & $2 \cdot 6$ \\
\hline Ca† & $7 \cdot 2$ \\
\hline $\mathrm{P} \dagger$ & $6 \cdot 0$ \\
\hline \multicolumn{2}{|c|}{ 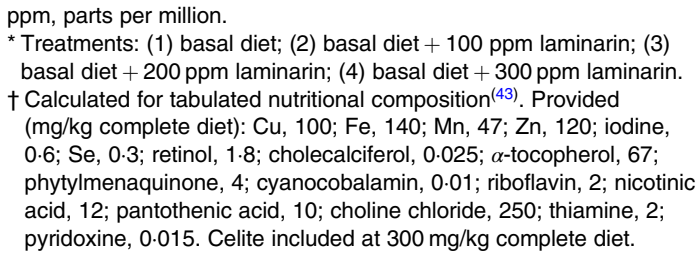 } \\
\hline
\end{tabular}

increased from 300 to $600 \mathrm{ppm}$. Ninety-six healthy piglets (progeny of meatline boars $\times$ (large white $\times$ landrace sows)) with an average weight of 8.4 (SD 1.09) kg were sourced from a commercial pig farm at weaning (28d of age) and housed in pens of three. The pigs were blocked based on weaning weight, litter of origin and sex and within each block assigned to one of the four dietary treatments (eight replicates/treatment). The basal diet contained $14.95 \mathrm{MJ} / \mathrm{kg}$ digestible energy, $190 \mathrm{~g} / \mathrm{kg}$ crude protein and $13.5 \mathrm{~g} / \mathrm{kg}$ total lysine. All amino acid requirements were met relative to lysine ${ }^{(15)}$. The ingredient composition and chemical analysis of the dietary treatments are presented in Table 1. The laminarin-rich extract was sourced from BioAtlantis Ltd. The extract was prepared by using water as an extraction solvent under optimum heating conditions (undisclosed method). A single extraction was performed from Laminaria spp. to produce the extract which contained $650 \mathrm{~g}$ of laminarin/kg DM, $181 \mathrm{~g}$ of fucoidan/ $\mathrm{kg} \mathrm{DM}, 4 \mathrm{~g}$ phlorotannins/kg DM, $60 \mathrm{~g}$ mannitol/ $\mathrm{kg}$ DM, $28 \mathrm{~g}$ alginates/kg DM and $77 \mathrm{~g}$ ash/kg DM. The appropriate quantity of the laminarin-rich extract was added to the basal diet to achieve 100, 200 or 300 ppm laminarin inclusion levels. 


\section{Housing and animal management}

The pigs were housed in fully slatted pens $(1.7 \times 1.2 \mathrm{~m})$. They were weighed at the beginning of the experiment ( $d 0$; day of weaning) and on days 7 and 14. The ambient environmental temperature within the house was thermostatically controlled at $30^{\circ} \mathrm{C}$ for the first $7 \mathrm{~d}$ and then reduced by $2^{\circ} \mathrm{C}$ for the remainder of the 2nd week, and the humidity was maintained at $65 \%$. Feed in meal form and water were available ad libitum from fourspace feeders and nipple drinkers. Aluminium trays were placed under feeders to catch any displaced feed and avoid feed wastage. Every day throughout the experiment, faecal scores (FS) were recorded in the individual pens by the same operator on a scale ranging from 1 to 5 . The following scoring system was used: $1=$ hard, firm faeces; 2 = slightly soft faeces; 3=soft, partially formed faeces; $4=$ loose, semi-liquid faeces and $5=$ watery, mucous-like faeces ${ }^{(16)}$.

\section{Sample collection}

On day 15, eight pigs (1 pig/pen) from the basal group and best-performing laminarin treatment ( $300 \mathrm{ppm}$ laminarin) group (based on ADG and ADFI) received a lethal injection with pentobarbitone sodium (Euthatal Solution, $200 \mathrm{mg} / \mathrm{ml}$; Merial Animal Health) at a rate of $0.71 \mathrm{ml} / \mathrm{kg}$ body weight to the cranial vena cava to humanely kill the animals. Euthanasia was completed by a competent person in a separate room away from sight and sound of the other pigs. The entire intestinal tract was immediately removed. Sections from the duodenum ( $10 \mathrm{~cm}$ from the stomach), the jejunum ( $60 \mathrm{~cm}$ from the stomach) and the ileum ( $15 \mathrm{~cm}$ from the caecum) were cut out and fixed in $10 \%$ neutral-buffered formalin. Digesta from the caecum and colon was collected into sterile containers (Sarstedt) and immediately frozen for subsequent quantification of total bacteria, Enterobacteriaceae, Bifidobacterium spp. and Lactobacillus spp. using quantitative PCR. In addition, tissue samples were taken from the duodenum, jejunum, ileum and colon to measure the gene expression of cytokines, digestive enzymes, nutrient transporters, mucins, tight junction components, pathogen recognition receptors, transcription regulators, appetite regulators, growth factors, kinases, ligand-dependent nuclear receptors, suppressors of cytokine signalling, peptidases, transmembrane receptors and viral defence genes using the Nanostring nCounter, which detects and counts target mRNA molecules using target-specific, colour-coded probe pairs ${ }^{(17)}$. Tissue sections of $1 \mathrm{~cm}^{2}$ from the duodenum, jejunum, ileum and colon were cut out, emptied by dissecting them along the mesentery and rinsed using sterile PBS (Oxoid). The tissue sections were stripped of the overlying smooth muscle before storage in $5 \mathrm{ml}$ RNAlater $\circledR$ solution (Applied Biosystems) overnight at $4^{\circ} \mathrm{C}$. The RNAlater $₫$ was removed before storing the samples at $-80^{\circ} \mathrm{C}$.

\section{Gut morphological analysis}

Preserved duodenal, jejunal and ileal tissue samples were prepared using standard paraffin-embedding techniques. The samples were sectioned at a thickness of $5 \mu \mathrm{m}$ and stained with haematoxylin-eosin. Villus height (VH) and crypt depth (CD) were measured in the stained sections ( $4 \times$ objective) using a light microscope fitted with an image analyser (Image-Pro Plus; Media Cybernetics). Measurements of fifteen well orientated and intact villi and crypts were taken for each segment. The VH was measured from the crypt-villus junction to the tip of the villus, and CD was measured from the cryptvillus junction to the base. Results are expressed as mean $\mathrm{VH}$ or $\mathrm{CD}$ in $\mu \mathrm{m}$.

\section{Gene expression}

RNA extraction. Total RNA was extracted from duodenal, jejunal, ileal and colonic tissue using TRIreagent (Sigma-Aldrich) according to the manufacturer's instructions. The crude RNA extract was further purified using the GenElute Mammalian Total RNA Miniprep Kit (Sigma-Aldrich) according to the manufacturer's instructions. A DNase removal step was included using an on-Column DNase 1 Digestion Set (Sigma-Aldrich). The total RNA was quantified using a Nanodrop-ND1000 Spectrophotometer (Thermo Scientific), and the purity was assessed by determining the ratio of the absorbance at 260 and $280 \mathrm{~nm}$. All total RNA samples had 260/280 $\mathrm{nm}$ ratios above $2 \cdot 0$.

Nanostring nCounter analysis. The small intestinal (duodenal, jejunal and ileal) tissues and colonic tissue were analysed using the Nanostring nCounter Analysis System (Nanostring Technologies). Two custom nCounter panels one for the small intestine and one for the colon were designed by our group and manufactured by Nanostring Technologies. The genes measured in the small intestine and large intestine are presented in the Supplementary material (online Supplementary Tables S1 and S2, respectively). The small intestinal codeset contained thirty-two target genes and five reference genes and the large intestinal codeset contained fifty-two target genes and eight reference genes. Both panels contained six positive and eight negative system controls

The expression profile of all target genes was performed for each sample in a single multiplexed hybridisation reaction, as originally described by Geiss et al. ${ }^{(17)}$. Briefly, prior to analysis, all samples were calibrated to $20 \mathrm{ng} / \mu \mathrm{l}$ using a Qubit fluorometer (Thermo Fisher Scientific). For the hybridisation reaction, a master mix was created by adding $70 \mu \mathrm{l}$ of hybridisation buffer to the reporter codeset, as per manufacturer instructions. Master mix $(8 \mu \mathrm{l})$, sample $(5 \mu \mathrm{l})$ (total RNA concentration $100 \mathrm{ng})$ and capture probeset $(2 \mu \mathrm{l})$ were added to each reaction tube and inverted to mix and spun down before incubation at $65^{\circ}$ $\mathrm{C}$ for $20 \mathrm{~h}$ in a Bio-rad thermocycler. Post-hybridisation processing was performed within the Nanostring nCounter prep station liquid handling robot which involves the removal of excess unbound probes and immobilisation of samples onto the internal surface of the sample cartridge. Following this imaging is completed in the digital analyser, which collects data by taking images of the immobilised fluorescent reporters in the sample cartridge with a CCD camera through a microscope objective lens. The analysis and normalisation of the raw Nanostring data were performed using nSolver Analysis Software v4.0 (Nanostring Technologies). Background was corrected for using 
background thresholding in which a threshold value is set and all counts which fall below that value are adjusted to match it. The background threshold value was estimated using the average count of the negative control probes in every reaction plus 2 standard deviations ${ }^{(18)}$. Target genes with raw counts below the threshold in more than two thirds of samples were excluded from the analysis. Raw counts were normalised using a combination of positive control normalisation and codeset content normalisation. The former accounts for errors such as pipetting errors, lot-to-lot variation in nCounter preparation plates and nCounter cartridges, while the latter uses reference/housekeeping genes to account for variability in the quantity and quality of sample RNA. Nanostring results (raw and normalised counts) were produced from RCC files using nSolver software V4.0.

\section{Microbial DNA extraction and quantitative PCR assay}

Microbial genomic DNA was extracted from the caecal and colonic digesta samples using a QIAamp DNA stool kit (Qiagen) in accordance with the manufacturer's instructions. The quantity and quality of DNA were assessed using a Nanodrop spectrophotometer (Thermo Scientific). For the quantitative PCR, standard curves were prepared with pooled aliquots of caecal and colonic digesta DNA as described previously by O'Shea et al. ${ }^{(19)}$. Domain, genus and family-specific primers were used to amplify the 16s rRNA gene. Primers for total bacteria, Lactobacillus spp., Bifidobacterium spp. and Enterobacteriaceae are presented in online Supplementary Table S3. The selected bacterial groups were estimated based on gene copy number in the digesta using quantitative PCR on the 7500 Fast Real-Time PCR System (Applied Biosystems). Quantitative PCR was carried out in a final reaction volume of $20 \mu \mathrm{l}$ containing $3 \mu \mathrm{l}$ template DNA, $1 \mu \mathrm{l}$ of forward and reverse primers (100 pM), $10 \mu \mathrm{l}$ SYBR Green PCR Master Mix (Applied Biosystems) and $5 \mu$ nuclease-free water. The thermal cycling conditions involved an initial denaturation step at $95^{\circ} \mathrm{C}$ for $10 \mathrm{~min}$ followed by forty cycles of $95^{\circ} \mathrm{C}$ for $15 \mathrm{~s}$ and $65^{\circ} \mathrm{C}$ for $1 \mathrm{~min}$. Dissociation curves confirmed the specificity of the final PCR products. All samples were prepared in duplicate, and the mean threshold cycle $(\mathrm{Ct})$ value was used for calculations. The estimates of gene copy number for selected bacteria were log-transformed and are presented as log gene copy number per $g$ of digesta.

\section{Volatile fatty acids}

The VFA concentrations in the caecal and colonic digesta were determined using GLC according to the method described by Pierce et $a l{ }^{(20)}$. A $1 \mathrm{~g}$ sample was diluted with distilled water $(2.5 \times$ weight of sample) and centrifuged at $1400 \boldsymbol{g}$ for $10 \mathrm{~min}$ (Sorvall GLC-2B laboratory centrifuge, DuPont). The subsequent supernatant $(1 \mathrm{ml})$ and internal standard $(1 \mathrm{ml} ; 0.05 \%$ 3-methyl- $n$-valeric acid in $0.15 \mathrm{~m}$ oxalic acid dihydrate) were mixed with $3 \mathrm{ml}$ of distilled water. The reaction mixture was centrifuged at $500 \boldsymbol{g}$ for $10 \mathrm{~min}$, and the supernatant was filtered through 0.45 polytetrafluoroethylene syringe filter into a chromatographic sample vial. An injection volume of $1 \mu \mathrm{l}$ was injected into a Varian 3800 GC equipped with an EC
1000 Grace column $(15 \mathrm{~m} \times 0.53 \mathrm{~mm}$ I.D) with $1.20 \mu \mathrm{m}$ film thickness. The temperature programme set was $75-95^{\circ} \mathrm{C}$ increasing by $3^{\circ} \mathrm{C} / \mathrm{min}$ and $95-200^{\circ} \mathrm{C}$ increasing by $20^{\circ} \mathrm{C} / \mathrm{min}$, which was held for $0.50 \mathrm{~min}$. The detector and injector temperature were 280 and $240^{\circ} \mathrm{C}$, respectively, while the total analysis time was $12.42 \mathrm{~min}$.

\section{Feed analysis}

The feed samples were milled through a $1 \mathrm{~mm}$ screen (Christy and Norris hammer mill). The DM of the feed was determined after drying overnight at $104^{\circ} \mathrm{C}$. Crude ash content was determined after ignition of a known weight of concentrate in a muffle furnace (Nabertherm) at $550^{\circ} \mathrm{C}$ for $6 \mathrm{~h}$. The crude protein content was determined as Kjeldahl $\mathrm{N} \times 6.25$ using the LECO FP 528 instrument. The neutral-detergent fibre content was determined according to Van Soest et al. ${ }^{(21)}$.

\section{Statistical analysis}

For sample size determination, the following power analysis formula was used: replication per treatment $=15.7 \times(\mathrm{CV} / \%$ difference $)^{2}$. The coefficient 15.7 is derived from statistical tables with a fixed experimental power of $80 \%$ and a significance value of $P<0.05$. The highest $\mathrm{CV}$ observed in comparable work was $14 \%$ for $\mathrm{ADG}^{(22)}$. In the present study, $D=20 \%$ is the difference that would be important to detect in selected variables including body weight change, gene expression and FS. Therefore, substituting the values into the above-mentioned formula:

Replication per treatment $(r)=15 \cdot 7 \times(14 / 20)^{2}=7 \cdot 7$ or

about 8 replicates/treatment.

The resulting data were initially checked for normality using the univariate procedure in SAS. The performance data and FS data were analysed by repeated measures using the mixed procedure of SAS and the model included fixed effects of treatment, time and their associated interactions. The initial weight was used as a covariate for the performance data. The data on intestinal morphology, microbial populations, gene expression and VFA were analysed using the GLM procedure of SAS, using weight at slaughter as a covariate. The model assessed the effect of treatment, followed by Bonferroni's test with the pig being the experimental unit. The probability level that denoted significance was $P<0 \cdot 05$. Data are presented as least-square means with their standard errors of the mean.

\section{Results}

\section{Performance and faecal scores}

The effects of laminarin supplementation on ADG, ADFI, G:F ratio and FS are presented in Table 2. From $\mathrm{d} 0-7$, there was no significant effect of laminarin on ADG or ADFI. From d7-14 to $\mathrm{d} 0-14$, the $300 \mathrm{ppm}$ laminarin supplemented pigs had a higher ADG $(P<0.05)$ than the basal group and higher ADFI $(P<0.05)$ than all other groups. The G:F ratio was unaffected by treatment. FS remained within the healthy range, 
Table 2. Effect of increasing inclusion levels of laminarin on pig growth performance and faecal scores

(Least-square mean values with their standard errors)

\begin{tabular}{clllll}
\hline & \multicolumn{5}{c}{ Laminarin inclusion level (ppm) } \\
\cline { 2 - 5 } & \multicolumn{1}{c}{0} & \multicolumn{1}{c}{100} & \multicolumn{1}{c}{200} & 300 & \\
\hline ADG $(\mathrm{kg})$ & & & & & \\
Day 0-7 & 0.098 & 0.076 & 0.057 & 0.133 & 0.029 \\
Day 7-14 & $0.223^{\mathrm{a}}$ & $0.273^{\mathrm{a}, \mathrm{b}}$ & $0.286^{\mathrm{a}, \mathrm{b}}$ & $0.304^{\mathrm{b}}$ & 0.030 \\
Day 0-14 & $0.160^{\mathrm{a}}$ & $0.175^{\mathrm{a}, \mathrm{b}}$ & $0.170^{\mathrm{a}, \mathrm{b}}$ & $0.218^{\mathrm{b}}$ & 0.018 \\
ADFI (kg) & & & & & \\
Day 0-7 & 0.216 & 0.198 & 0.181 & 0.246 & 0.026 \\
Day 7-14 & $0.422^{\mathrm{a}}$ & $0.477^{\mathrm{a}, \mathrm{b}}$ & $0.469^{\mathrm{a}, \mathrm{b}}$ & $0.513^{\mathrm{b}}$ & 0.026 \\
Day 0-14 & $0.318^{\mathrm{a}}$ & $0.338^{\mathrm{a}}$ & $0.323^{\mathrm{a}}$ & $0.379^{\mathrm{b}}$ & 0.012 \\
G:F & & & & & \\
Day 0-7 & $0.422^{\mathrm{a}, \mathrm{b}}$ & $0.326^{\mathrm{a}, \mathrm{b}}$ & $0.267^{\mathrm{b}}$ & $0.498^{\mathrm{a}}$ & 0.068 \\
Day 7-14 & 0.513 & 0.568 & 0.642 & 0.590 & 0.069 \\
Day 0-14 & 0.468 & 0.448 & 0.454 & 0.544 & 0.054 \\
FS & & & & & \\
Day 0-7 & 3.0 & 2.9 & 2.9 & 2.8 & 0.109 \\
Day 7-14 & 3.1 & 2.9 & 2.8 & 2.8 & 0.109 \\
Day 0-14 & 2.8 & 2.7 & 2.8 & 2.7 & 0.086 \\
\hline
\end{tabular}

ppm, parts per million; $A D G$, average daily gain; $A D F I$, average daily feed intake; $G: F$, gain to feed ratio; $F S$, faecal score.

a,b Mean values within a row with unlike superscript letters were significantly different $(P<0.05)$.

${ }^{*} A$ total of eight replicates were used per treatment group (replicate $=$ pen, 3 pigs $/$ pen).

Table 3. Effect of laminarin on villus height (VH) and crypt depth (CD) in the small intestine

(Least-square mean values with their standard errors)

\begin{tabular}{|c|c|c|c|c|}
\hline & \multicolumn{2}{|c|}{$\begin{array}{l}\text { Laminarin inclusion } \\
\text { level (ppm) }\end{array}$} & \multirow[b]{2}{*}{ SEM } & \multirow[b]{2}{*}{$P$} \\
\hline & 0 & 300 & & \\
\hline \multicolumn{5}{|l|}{ Duodenum } \\
\hline $\mathrm{VH}(\mu \mathrm{m})$ & $213 \cdot 10$ & 262.52 & 14.08 & 0.025 \\
\hline$C D(\mu \mathrm{m})$ & 112.88 & 144.46 & 6.548 & 0.004 \\
\hline VH:CD & 1.95 & 1.83 & 0.124 & 0.490 \\
\hline \multicolumn{5}{|l|}{ Jejunum } \\
\hline $\mathrm{VH}(\mu \mathrm{m})$ & 212.42 & 264.03 & $15 \cdot 79$ & 0.035 \\
\hline $\mathrm{CD}(\mu \mathrm{m})$ & $135 \cdot 27$ & 144.04 & 8.917 & 0.497 \\
\hline VH:CD & 1.59 & 1.86 & 0.111 & 0.097 \\
\hline \multicolumn{5}{|l|}{ Ileum } \\
\hline $\mathrm{VH}(\mu \mathrm{m})$ & 242.43 & $271 \cdot 12$ & $15 \cdot 73$ & 0.215 \\
\hline $\mathrm{CD}(\mu \mathrm{m})$ & $125 \cdot 68$ & 138.05 & 9.07 & 0.349 \\
\hline VH:CD & 1.98 & $2 \cdot 01$ & 0.153 & 0.916 \\
\hline
\end{tabular}

ppm, parts per million.

* A total of eight replicates were used per treatment.

and there was no difference in FS between the basal and the laminarin supplemented diets $(P>0.05)$ during the 14 -d experimental period.

\section{Small intestinal morphology}

The effects of laminarin supplementation on villous height and $\mathrm{CD}$ in the small intestine are presented in Table 3. Pigs offered the $300 \mathrm{ppm}$ laminarin diet had increased villous height in the duodenum and jejunum $(P<0.05)$ and increased CD in the duodenum $(P<0.01)$ compared with pigs offered the basal diet. No effect on morphology was observed in the ileum $(P>0.05)$.
Table 4. Effect of laminarin on selected microbial populations in the caecal and colonic digesta

(Least-square mean values with their standard errors)

\begin{tabular}{|c|c|c|c|c|}
\hline & \multicolumn{2}{|c|}{$\begin{array}{c}\text { Laminarin } \\
\text { inclusion } \\
\text { level }(\mathrm{ppm})^{\star}\end{array}$} & \multirow[b]{2}{*}{ SEM } & \multirow[b]{2}{*}{$P$} \\
\hline & 0 & 300 & & \\
\hline \multicolumn{5}{|c|}{ Caecal bacterial numbers (log GCN/g digesta) } \\
\hline Lactobacillus spp. & 8.34 & 8.58 & 0.217 & 0.442 \\
\hline Bifidobacterium spp. & 6.52 & 6.51 & 0.074 & 0.859 \\
\hline Enterobacteriaceae & $8 \cdot 30$ & 7.59 & 0.230 & 0.047 \\
\hline Total bacteria & $8 \cdot 90$ & 8.84 & 0.105 & 0.676 \\
\hline \multicolumn{5}{|c|}{ Colonic bacterial numbers (log GCN/g digesta) } \\
\hline Lactobacillus spp. & $8 \cdot 19$ & 8.57 & 0.121 & 0.042 \\
\hline Bifidobacterium spp. & 5.57 & 5.49 & 0.057 & 0.348 \\
\hline Enterobacteriaceae & $8 \cdot 32$ & $7 \cdot 82$ & 0.261 & 0.200 \\
\hline Total bacteria & $9 \cdot 25$ & $9 \cdot 13$ & 0.091 & 0.372 \\
\hline
\end{tabular}

ppm, parts per million; GCN, gene copy number.

${ }^{*} \mathrm{~A}$ total of eight replicates were used per treatment.

Table 5. Effect of laminarin inclusion on total and molar proportions of volatile fatty acids (VFA) in colonic digesta

(Least-square mean values with their standard errors)

\begin{tabular}{|c|c|c|c|c|}
\hline & \multicolumn{2}{|c|}{$\begin{array}{l}\text { Laminarin inclusion } \\
\text { level }(\mathrm{ppm})^{\star}\end{array}$} & \multirow[b]{2}{*}{ SEM } & \multirow[b]{2}{*}{$P$} \\
\hline & 0 & 300 & & \\
\hline \multicolumn{5}{|c|}{ VFA (mmol// digesta) } \\
\hline Total & $130 \cdot 71$ & 157.83 & $7 \cdot 845$ & 0.027 \\
\hline Acetate & 95.36 & $111 \cdot 13$ & 4.786 & 0.034 \\
\hline Propionate & 19.05 & $23 \cdot 24$ & 1.659 & 0.094 \\
\hline Butyrate & $12 \cdot 64$ & $18 \cdot 41$ & 1.997 & 0.059 \\
\hline Isobutyrate & 1.04 & 1.23 & 0.218 & 0.534 \\
\hline Isovalerate & 0.90 & 1.21 & 0.133 & 0.122 \\
\hline Valerate & 1.72 & $2 \cdot 77$ & 0.423 & 0.101 \\
\hline \multicolumn{5}{|c|}{ Molar proportions } \\
\hline Acetate & 0.732 & 0.707 & 0.013 & 0.206 \\
\hline Propionate & 0.146 & 0.139 & 0.007 & 0.502 \\
\hline Butyrate & 0.083 & 0.113 & 0.007 & 0.006 \\
\hline Isobutyrate & 0.008 & 0.007 & 0.001 & 0.605 \\
\hline Isovalerate & 0.007 & 0.007 & 0.001 & 0.837 \\
\hline Valerate & 0.013 & 0.017 & 0.002 & 0.170 \\
\hline
\end{tabular}

ppm, parts per million.

${ }^{*} \mathrm{~A}$ total of eight replicates were used per treatment.

\section{Microbiology and volatile fatty acids}

The effects of laminarin supplementation on selected microbial populations in the caecum and colon are presented in Table 4. There was a reduction in the Enterobacteriaceae population in the caecum $(P<0.05)$ and an increase in Lactobacillus spp. in the colon $(P<0.05)$ of laminarin supplemented pigs compared with the basal group. There was no effect of laminarin on the numbers of total bacteria, Lactobacillus spp. or Bifidobacterium spp. in the caecum $(P>0.05)$ or the numbers of total bacteria, Enterobacteriaceae or Bifidobacterium spp. in the colon $(P>0.05)$.

The effects of laminarin supplementation on the concentrations and molar proportions of VFA are presented in Table 5. In the colon, pigs offered laminarin had increased concentrations of total VFA $(P<0.05)$ and acetate $(P<0.05)$ and an increase in the molar proportion of butyrate $(P<0 \cdot 01)$. 
Table 6. Effect of laminarin inclusion on the expression of nutrient transporters in the duodenum, jejunum and ileum; the expression of immune markers in the duodenum, ileum and colon; and appetite regulators in the ileum

(Least square means with their standard errors)

\begin{tabular}{|c|c|c|c|c|c|}
\hline & & \multicolumn{2}{|c|}{$\begin{array}{l}\text { Laminarin inclusion } \\
\text { level }(\mathrm{ppm})^{\star}\end{array}$} & \multirow[b]{2}{*}{ SEM } & \multirow[b]{2}{*}{$P$} \\
\hline & & 0 & 300 & & \\
\hline \multicolumn{6}{|c|}{ Nutrient transporters } \\
\hline \multirow[t]{3}{*}{ Duodenum } & $S L C 2 A 8$ & $226 \cdot 76$ & 408.87 & 51.06 & 0.024 \\
\hline & SLC2A2 & $940 \cdot 21$ & 2527.69 & $515 \cdot 41$ & 0.049 \\
\hline & $S L C 2 A 7$ & 99.26 & 247.27 & 45.89 & 0.040 \\
\hline \multirow[t]{3}{*}{ Jejunum } & SLC6A19 & 1195.83 & 2171.72 & $318 \cdot 73$ & 0.050 \\
\hline & SLC15A1 & 1047.49 & 2798.42 & 545.05 & 0.041 \\
\hline & $F A B P 2$ & 9854.47 & 28613.82 & 5521.06 & 0.032 \\
\hline \multirow[t]{2}{*}{ lleum } & SLC6A19 & $2650 \cdot 79$ & $1814 \cdot 40$ & $275 \cdot 94$ & 0.048 \\
\hline & SLC5A8 & $2633 \cdot 70$ & $1806 \cdot 30$ & 229.07 & 0.021 \\
\hline Colon & SLC16A1 & 4859.63 & 8021.43 & $847 \cdot 29$ & 0.019 \\
\hline \multicolumn{6}{|c|}{ Appetite regulators } \\
\hline Ileum & CCK & 26.63 & 54.20 & $7 \cdot 38$ & 0.018 \\
\hline \multicolumn{6}{|c|}{ Tight junctions and immune markers } \\
\hline \multirow[t]{4}{*}{ Duodenum } & CLDN5 & 65.53 & 52.68 & 3.74 & 0.029 \\
\hline & TJP1 & 1087.48 & 913.60 & 33.78 & 0.003 \\
\hline & CLDN3 & 1899.47 & $1305 \cdot 23$ & 189.50 & 0.041 \\
\hline & TJP1 & 1159.50 & 958.94 & 60.00 & 0.031 \\
\hline \multirow{3}{*}{ Ileum } & MUC1 & $42 \cdot 25$ & 23.19 & 5.01 & 0.016 \\
\hline & MUC2 & $8246 \cdot 34$ & $5401 \cdot 73$ & 566.08 & 0.003 \\
\hline & TLR2 & 938.68 & 644.92 & 96.00 & 0.046 \\
\hline \multirow[t]{2}{*}{ Colon } & CLEC7A & 79.54 & 48.01 & $9 \cdot 25$ & 0.031 \\
\hline & PPARG & $1546 \cdot 10$ & 1773.47 & 73.37 & 0.046 \\
\hline
\end{tabular}

ppm, parts per million; SLC2A8, GLUT 8; CLDN5, claudin 5; TJP1, tight junction protein 1; TGFB1, transforming growth factor beta 1; SLC2A2, GLUT 2; SLC2A7,

GLUT 7; SLC6A19, neutral amino acid transporter; SLC15A1, peptide transporter 1; $F A B P 2$, fatty acid binding protein 2; SLC5A8, sodium monocarboxylate transporter; $C C K$, cholecystokinin; $M U C 1$, mucin 1; MUC2, mucin 2; CLDN3, claudin 3; TJP1, tight junction protein 1; TLR2, toll-like receptor 2; $S L C 16 A 1$, monocarboxylate transporter 1; CLEC7A, c-type lectin domain containing 7a; PPARG, PPAR receptor.

${ }^{*}$ A total of eight replicates were used per treatment.

\section{Gene expression}

While the Nanostring nCounter panels used in the present study assessed the expression of a broad range of genes, only the genes with relevance to gastrointestinal functionality in the post-weaning period are included in the results. The genes that were differentially expressed are presented in Table 6 with all expression data for relevant genes presented in the Supplementary material (online Supplementary Tables S4-S7).

Nutrient and volatile fatty acids transporter gene expression. In the duodenum, laminarin supplementation increased the expression of the GLUT 8 (SLC2A8; $P<0.05$ ). In the jejunum, laminarin supplementation increased the expression of GLUT 2 (SLC2A2; $P<0.05$ ), GLUT 7 (SLC2A7; $P<0.05$ ), peptide transporter 1 (SLC15A1; $P<0.05$ ), neutral amino acid transporter 19 (SLC6A19; $P=0.05$ ) and fatty acid binding protein 2 (FABP2; $P<0.05$ ). In the ileum, laminarin supplementation reduced the expression of neutral amino acid transporter 19 (SLC6A19) and sodium monocarboxylate transporter $(S L C 5 A 8 / S M C T 1)(P<0.05)$.

In the colon, laminarin supplementation increased the expression of monocarboxylate transporter 1 (SLC16A1; P<0.05).
Appetite regulator gene expression. In the ileum, laminarin supplementation increased the expression of cholecystokinin (CCK; $P<0.05)$. There were no differences in the duodenum or jejunum.

Tight junction and immune marker gene expression. In the duodenum, laminarin supplementation reduced the expression of claudin-5 (CLDN5; $P<0.05$ ), tight junction protein 1 (zona occludens 1) (TJP1; $P<0.01), N F-\kappa B 1(P<0.05)$ and transforming growth factor beta 1 (TGFB1; $P<0.05)$. In the ileum, laminarin supplementation reduced the expression of claudin-3 (CLDN3; $P<0.05)$, TJP1 $(P<0 \cdot 05)$, toll-like receptor 2 (TLR2; $P<0.05)$, mucin 1 (MUC1; $P<0.05)$ and mucin 2 (MUC2; $P<0 \cdot 01)$.

In the colon, laminarin supplementation reduced the expression of Dectin-1/C-type lectin domain containing 7A $(C L E C 7 A ; P<0.05)$, while it increased the expression of PPAR gamma (PPARG; $P<0.05)$.

\section{Discussion}

The hypothesis of the present study was that laminarin supplementation would improve performance and reduce intestinal dysfunction during the first $14 \mathrm{~d}$ post-weaning, by enhancing intestinal morphology, reducing Enterobacteriaceae, increasing the expression of nutrient transporters and digestive enzymes and reducing the expression of pro-inflammatory cytokines. The positive response observed with laminarin supplementation, including increased $\mathrm{VH}$ in the duodenum and jejunum, reduced caecal Enterobacteriaceae, increased colonic lactobacilli and butyrate concentration and increased expression of VFA, glucose, fatty acid and protein transporters, supports the hypothesis that laminarin supplementation reduces postweaning intestinal dysfunction. The present study also confirms that $300 \mathrm{ppm}$ is the optimum of the tested inclusion levels of laminarin, to improve post-weaning pig performance.

The increased feed intake in the $300 \mathrm{ppm}$ laminarin supplemented group is a major factor driving the improved growth performance in these animals. The oral consumption of food and its physical presence in the GIT is necessary for structural and functional maintenance of the intestinal mucosa ${ }^{(1)}$, as villous atrophy and crypt hyperplasia are the consequences of low feed intake post-weaning ${ }^{(1,2)}$. In the present study, laminarin supplementation also increased villous height in the duodenum and jejunum. This increase was independent of live weight. Longer villi are associated with increased digestive and absorptive function ${ }^{(23)}$. In the present study, laminarin supplementation increased the expression of the glucose transporters $S L C 2 A 8 /$ GLUT8 (duodenum), SLC2A2/GLUT2 and SLC2A7/GLUT7 (jejunum), the peptide transporter SLC15A1/PEPT1 (jejunum), the amino acid transporter SLC6A19 (duodenum and ileum) and the long-chain fatty acid transporter FABP2 (jejunum). Nutrient transporters are responsible for the transport of nutrients into the bloodstream following digestion by digestive enzymes. It is possible that the increase in sugar, fatty acid, peptide and amino acid transporters improved energy and protein 
utilisation in pigs supplemented with laminarin. Unfortunately, the digestibility of these nutrients was not measured in the present study, due to the low quantity of digesta in the ileum at the time of sampling. It also suggests that laminarin supplemented pigs may have adapted more quickly to their postweaning diet which is primarily comprised of carbohydrates (wheat and maize) and protein (soya bean meal and soya protein concentrate) by up-regulating the expression of the appropriate nutrient transporters. It is commonly considered that the small intestine responds to dietary changes by altering the expression of digestive enzymes and nutrient transporters, for example, an increase in dietary carbohydrates may cause an up-regulation of hexose transporters to promote an increase in sugar absorption $^{(24)}$.

Feed intake is regulated through the release of food intakeregulatory peptides from the GIT. One such peptide is CCK, which induces satiety and reduces food intake ${ }^{(25,26)}$. The up-regulation of $C C K$ in the ileum of laminarin supplemented pigs suggests that feed intake requirements were satisfied in this group. CCK is mainly stimulated by fats and proteins ${ }^{(25,26)}$, and the increase in FABP2 and PEPT1 in the jejunum of laminarin supplemented pigs may indicate that there was sufficient absorption of these nutrients prior to reaching the ileum.

The relevance of measuring Enterobacteriaceae populations as an indicator of pathogenic bacteria is widely debated; however, an increase in Enterobacteriaceae has been reported in diarrhoeic pigs post-weaning ${ }^{(27)}$. The Enterobacteriaceae family includes opportunistic pathogens such as Salmonella enterica serovar Typhimurium and enterotoxigenic Escherichia coli which can induce intestinal inflammation in pigs $^{(28)}$ and enterotoxigenic Escherichia coli is reported to be one of the main causative factors of post-weaning diarrhoea in piglets ${ }^{(29,30)}$. The ability of $\beta$-glucans (laminarin) to agglutinate certain bacterial species and prevent their attachment to the intestinal epithelium was previously reviewed by Sweeney \& O'Doherty ${ }^{(31)}$. Although many members of the Enterobacteriaceae family are commensals, the potential to reduce pathogenic Enterobacteriaceae without affecting beneficial bacterial populations such as the bifidobacteria and lactobacilli may have contributed to the improved growth performance in the laminarin treatment group. However, future studies with laminarin will investigate its effects on specific pathogens using 16S rRNA sequencing to fully elucidate its prebiotic and anti-microbial potential.

Of significance was the increase in lactobacilli numbers and increased concentration of total VFA, acetate and butyrate, as well as the increased expression of the butyrate transporter monocarboxylate transporter 1 (MCT1/SLC16A1)) with laminarin supplementation in the colon. Lactobacilli were enumerated as a reflection of changes in the population structure of beneficial bacteria as they can enhance host GIT health through the competitive exclusion of pathogenic bacteria, antioxidant activities and aiding the regulation of the immune system ${ }^{(32)}$. The production of VFA allows for greater energy utilisation by recovering energy from carbohydrates which were not digested in the small intestine ${ }^{(33)}$. VFA are essential for the growth and proliferation of colonocytes ${ }^{(34)}$, and butyrate is the preferential energy source of the colonocytes ${ }^{(35)}$. Butyrate has also other intestinal health-enhancing properties such as the facilitation of the absorption of water, $\mathrm{Na}$ and $\mathrm{K}^{(33)}$, regulation of gene expression by inhibiting the expression of histone deacetylases, enhancing the expression of host defence peptides, and antibacterial activity ${ }^{(33,36)}$. As butyrate plays an important role in the maintenance of colonic health, the expression of SLC16A1 and absorption of butyrate can have an important impact on colonic homeostasis ${ }^{(37)}$.

Laminarin inclusion induced a number of positive immunomodulatory effects in the small intestine of the post-weaning pig. Laminarin inclusion was associated with a down-regulation of the transcription factor $N F-\kappa B 1$ and the growth factor TGFB1 in the duodenum. $N F-\kappa B 1$ induces the expression of proinflammatory cytokines ${ }^{(38)}$, and TGFB1 is involved in mucosal cell growth, differentiation, migration and epithelial restitution $^{(39)}$. TGFB1 has been shown to be up-regulated in the 1st week post-weaning and then returns to pre-weaning levels ${ }^{(39)}$. The expression of genes involved in the formation of tight junctions CLDN5 (duodenum), TJP1 (duodenum and ileum) and $C L D N 3$ (ileum) was also reduced in laminarin supplemented pigs. An increase in the expression of these genes likely functions to enhance the epithelial barrier during periods of challenge; previously, the expression of TJP1, CLDN3 and $O C L N$ was transiently increased in heat stressed pigs and associated with increased LPS permeability and reduced villous height $^{(40)}$. The TGFB1, CLDN3, CLDN5 and TJP1 expression data in association with the villous architecture data suggest that laminarin supplemented pigs may have achieved epithelial maturity in the small intestine faster than the basal fed animals. However, these changes in gene expression were minor, and while the reductions were statistically significant, the biological impact of their reduction is probably limited. The expression of TLR2, MUC1 and MUC2 was down-regulated in the ileum of laminarin supplemented pigs. TLR2 recognises microbialassociated molecular patterns of yeast and bacteria, and it has been previously shown to be up-regulated in the ileum immediately post-weaning and subsequently declines ${ }^{(41)}$. Mucin secretion can be initiated by a number of factors, including microbes, microbial products, cytokines and reactive oxygen species ${ }^{(42)}$, indicating it is up-regulated in response to challenge. Together, the reduction in mucins and TLR2 suggests reduced exposure to pathogens in laminarin supplemented animals. Considering FS remained within a healthy range throughout the experiment, it is unlikely the immune system of either group was challenged. Nonetheless, these results suggest laminarin supplementation may have beneficial immunomodulatory effects under more challenging conditions.

\section{Conclusion}

In conclusion, improved ADG and ADFI suggest $300 \mathrm{ppm}$ is the optimum of the tested inclusion levels of laminarin from a laminarin-rich extract ( $65 \%$ laminarin) to enhance post-weaning performance. The increased VH, expression of nutrient transporters, populations of lactobacilli and butyrate concentrations, in conjunction with reduced populations of Enterobacteriaceae and reduced expression of immune markers and pathogen recognition receptors, suggest that laminarin supplementation 
reduced intestinal dysfunction in the post-weaning period. Thus, laminarin has potential as an alternative to in-feed medications for piglets in the post-weaning period. Furthermore, laminarin has potential as a dietary supplement for other monogastric animals and humans for the treatment or prevention of diseases related to intestinal dysfunction.

\section{Acknowledgements}

This work was funded by the Science Foundation Ireland (SFI) (grant number: 14/IA/2548).

The authors' contributions were as follows: R. R. performed the experiment, collected the samples, carried out the laboratory analyses and wrote the manuscript; J. V. O. D. designed the experiment, supervised data collection and statistical analyses and corrected the manuscript; T. S. designed the experiment and corrected the manuscript; S. M., K. T. and G. R. contributed to sample collection and laboratory analyses. All authors approved the final version of the manuscript.

None of the authors had a financial or personal conflict of interest in relation to the present study.

\section{Supplementary material}

For supplementary material referred to in this article, please visit https://doi.org/10.1017/S0007114519002678

\section{References}

1. Pluske JR, Hampson DJ \& Williams IH (1997) Factors influencing the structure and function of the small intestine in the weaned pig: a review. Livest Prod Sci 51, 215-236.

2. Lallès J, Boudry G, Favier C, et al. (2004) Gut function and dysfunction in young pigs: physiology. Anim Res 53, 301-316.

3. Pluske JR (2013) Feed- and feed additives-related aspects of gut health and development in weanling pigs. J Anim Sci Biotechnol 4, 1.

4. Moeser AJ, Pohl CS \& Rajput M (2017) Weaning stress and gastrointestinal barrier development: implications for lifelong gut health in pigs. Anim Nutr 3, 313-321.

5. Pluske JR, Turpin DL \& Kim JC (2018) Gastrointestinal tract (gut) health in the young pig. Anim Nutr 4, 187-196.

6. O'Doherty JV, Bouwhuis MA \& Sweeney T (2017) Novel marine polysaccharides and maternal nutrition to stimulate gut health and performance in post-weaned pigs. Anim Prod Sci 57, 2376-2385.

7. Kim JC, Hansen CF, Mullan BP, et al. (2012) Nutrition and pathology of weaner pigs: nutritional strategies to support barrier function in the gastrointestinal tract. Anim Feed Sci Technol 173, 3-16.

8. Long L, Chen J, Zhang Y, et al. (2017) Correction: comparison of porous and nano zinc oxide for replacing high-dose dietary regular zinc oxide in weaning piglets. PLOS ONE 12, e0188587.

9. European Parliament (2018) Veterinary medicines: another step in fighting antibiotic resistance. http://www.europarl. europa.eu/news/en/headlines/society/20181018STO16580/ veterinary-medicines-fighting-antibiotic-resistance (accessed May 2019).

10. Deville C, Gharbi M, Dandrifosse G, et al. (2007) Study on the effects of laminarin, a polysaccharide from seaweed, on gut characteristics. J Sci Food Agric 87, 1717-1725.
11. Rioux LE, Turgeon SL \& Beaulieu M (2010) Structural characterization of laminaran and galactofucan extracted from the brown seaweed Saccharina longicruris. Phytochemistry $\mathbf{7 1}$, $1586-1595$.

12. Walsh AM, Sweeney T, O'Shea CJ, et al. (2013) Effect of dietary laminarin and fucoidan on selected microbiota, intestinal morphology and immune status of the newly weaned pig. BrJ Nutr 110, 1630-1638.

13. Garcia-Vaquero M, Rajauria G, O’Doherty JV, et al. (2017) Polysaccharides from macroalgae: recent advances, innovative technologies and challenges in extraction and purification. Food Res Int 99, 1011-1020.

14. Smith AG, O'Doherty JV, Reilly P, et al. (2011) The effects of laminarin derived from Laminaria digitata on measurements of gut health: selected bacterial populations, intestinal fermentation, mucin gene expression and cytokine gene expression in the pig. Br J Nutr 105, 669-677.

15. National Research Council (2012) Nutrient Requirements of Swine, 11th ed. Washington, DC: National Academies Press.

16. Walsh AM, Sweeney T, O'Shea CJ, et al. (2013) Effect of supplementing varying inclusion levels of laminarin and fucoidan on growth performance, digestibility of diet components, selected faecal microbial populations and volatile fatty acid concentrations in weaned pigs. Anim Feed Sci Tech 183, 151-159.

17. Geiss GK, Bumgarner RE, Birditt B, et al. (2008) Direct multiplexed measurement of gene expression with color-coded probe pairs. Nat Biotechnol 26, 317-325.

18. Vigors S, JV OD, Ryan M, et al. (2019) Analysis of the basal colonic innate immune response of pigs divergent in feed efficiency and following an ex vivo lipopolysaccharide challenge. Physiol Genomics 51, 443-448.

19. O'Shea CJ, Sweeney T, Bahar B, et al. (2012) Indices of gastrointestinal fermentation and manure emissions of growing-finishing pigs as influenced through singular or combined consumption of Lactobacillus plantarum and inulin. J Anim Sci 90, 3848-3857.

20. Pierce KM, Sweeney T, Callan JJ, et al. (2006) The effect of inclusion of a high lactose supplement in finishing diets on nutrient digestibility, nitrogen excretion, volatile fatty acid concentrations and ammonia emission from boars. Anim Feed Sci Tech 125, 45-60.

21. Van Soest PVR, Robertson JB \& Lewis BA (1991) Methods for dietary fiber, neutral detergent fiber, and nonstarch polysaccharides in relation to animal nutrition. J Dairy Sci 74, 3583-3597.

22. Heim G, Walsh AM, Sweeney T, et al. (2014) Effect of seaweed-derived laminarin and fucoidan and zinc oxide on gut morphology, nutrient transporters, nutrient digestibility, growth performance and selected microbial populations in weaned pigs. Br J Nutr 111, 1577-1585.

23. Jayaraman B \& Nyachoti CM (2017) Husbandry practices and gut health outcomes in weaned piglets: a review. Anim Nutr 3, 205-211.

24. Drozdowski L \& Thomson AB (2006) Intestinal mucosal adaptation. World J Gastroenterol 12, 4614-4627.

25. Wang Y, Chandra R, Samsa LA, et al. (2011) Amino acids stimulate cholecystokinin release through the $\mathrm{Ca}^{2+}$-sensing receptor. Am J Physiol Gastrointest Liver Physiol 300, G528G537.

26. Prinz P \& Stengel A (2017) Control of food intake by gastrointestinal peptides: mechanisms of action and possible modulation in the treatment of obesity. J Neurogastroenterol Motil 23, 180-196. 
27. Dou S, Gadonna-Widehem P, Rome V, et al. (2017) Characterisation of early-life fecal microbiota in susceptible and healthy pigs to post-weaning diarrhoea. PLOS ONE 12, e0169851.

28. Guevarra RB, Lee JH, Lee SH, et al. (2019) Piglet gut microbial shifts early in life: causes and effects. J Anim Sci Biotechnol 10, 1.

29. Gresse R, Chaucheyras-Durand F, Fleury MA, et al. (2017) Gut microbiota dysbiosis in postweaning piglets: understanding the keys to health. Trends Microbiol 25, 851-873.

30. Rhouma M, Fairbrother JM, Beaudry F, et al. (2017) Post weaning diarrhea in pigs: risk factors and non-colistin-based control strategies. Acta Vet Scand 59, 31.

31. Sweeney T \& O'Doherty JV (2016) Marine macroalgal extracts to maintain gut homeostasis in the weaning piglet. Domest Anim Endocrin 56, S84-S89.

32. Valeriano VDV, Balolong MP \& Kang D-K (2017) Probiotic roles of Lactobacillus sp. in swine: insights from gut microbiota. J Appl Microbiol 122, 554-567.

33. Bedford A \& Gong J (2018) Implications of butyrate and its derivatives for gut health and animal production. Anim Nutr 4, 151-159.

34. Liu YL (2015) Fatty acids, inflammation and intestinal health in pigs. J Anim Sci Biotechnol 6, 41

35. Williams BA, Verstegen MWA \& Tamminga S (2001) Fermentation in the large intestine of single-stomached animals and its relationship to animal health. Nutr Res Rev 14, 207-227.

36. Xiong X, Tan B, Song M, et al. (2019) Nutritional intervention for the intestinal development and health of weaned pigs. Front Vet Sci 6, 46.

37. Cuff MA, Lambert DW \& Shirazi-Beechey SP (2002) Substrate-induced regulation of the human colonic monocarboxylate transporter, MCT1. J Physiol 539, 361-371.

38. Liu T, Zhang L, Joo D, et al. (2017) NF-kappaB signaling in inflammation. Signal Transduct Target Ther $\mathbf{2}, 17023$

39. Xiao K, Song ZH, Jiao LF, et al. (2014) Developmental changes of TGF- $\beta 1$ and Smads signaling pathway in intestinal adaption of weaned pigs. PLOS ONE $\mathbf{9}$, e104589

40. Pearce SC, Mani V, Weber TE, et al. (2013) Heat stress and reduced plane of nutrition decreases intestinal integrity and function in pigs. J Anim Sci $\mathbf{9 1}, 5183-5193$.

41. Tao X, Xu Z \& Wan J (2015) Intestinal microbiota diversity and expression of pattern recognition receptors in newly weaned piglets. Anaerobe 32, 51-56.

42. Kim YS \& Ho SB (2010) Intestinal goblet cells and mucins in health and disease: recent insights and progress. Curr Gastroenterol Rep 12, 319-330.

43. Sauvant D, Perez JM \& Tran G (2004) Table of Composition and Nutritional Value of Feed Materials. Pigs, Poultry, Cattle, Sheep, Goats, Rabbits, Horses, Fish. Wageningen, The Netherlands: Wageningen Academic Publishers. 